\section{Microanatomical Observations of Hair Characteristics of Red Fox (Vulpes vulpes), Golden Jackal (Canis aureus), and Gray Wolf (Canis lupus): A Comparative Study}

\author{
Ahmet Arpacik \\ Department of Wildlife Ecology and Management, Karadeniz Technical University, \\ Trabzon, Turkey
}

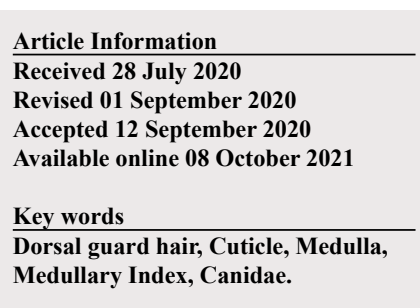

\section{A B S T R A C T}

Dorsal guard hairs from three canid species that included red fox (Vulpes vulpes), golden jackal (Canis aureus), and gray wolf (Canis lupus) found in Turkey were characterized using light microscopy to study hair features, including cuticle and medullary patterns, medullary index, and hair length and root. The morphological features of the medulla and cuticle structures were quite similar for the three species, but a distinct difference was observed in the medulla structure. While the medullary structures of both $C$. aureus and $C$. lupus had a vacuolated structure, a multiseriate structure was observed in the $V$. vulpes. The average longest hairs (means \pm standard errors [SE]) were observed to be $6.66 \pm 1.22,6.02 \pm 0.75$, and $5.56 \pm 5.57 \mathrm{~cm}$ in $C$. aureus, $V$. vulpes, and $C$. lupus, respectively. The highest medullary index $(0.72$ $\pm 0.52 \mu \mathrm{m})$ was recorded in $C$. aureus followed by $V$. vulpes $(0.70 \pm 0.56 \mu \mathrm{m})$ with the lowest in $C$. lupus $(0.42 \pm 0.64 \mu \mathrm{m})$. Hair root diameter values were determined as $136.27 \pm 29.25,102.30 \pm 17.19$, and $62.23 \pm 10.37 \mu \mathrm{m}$ in C. lupus, C. aureus, and $V$. vulpes. Based on the one-way analysis of variance, significant differences were identified in both hair length and diameter, medullary diameter and index, and hair root diameter values among the three species $(\mathrm{P}<0.05)$.

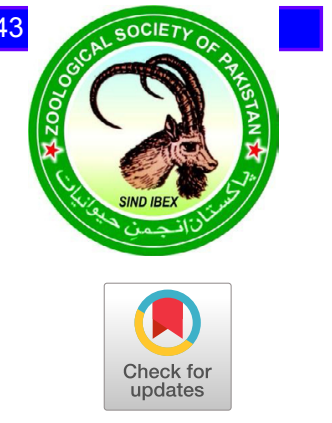

\section{INTRODUCTION}

$\mathrm{M}$ icroanatomical hair identification of mammalian species has relevant applications in forensic medicine, taxonomy, paleontology, zooarchaeology, anthropology, and wildlife studies (Lyne and Short, 1965; Hardy, 1992; Meyer et al., 2002; Chang et al., 2005; De Marinis and Asprea, 2006; Tridicio et al., 2014). The purpose of morphological and morphometric identification of animal hair is to classify animal species from an unknown hair pattern in a special taxon based on welldefined, genetically-based features (Tridicio et al, 2014).

For identification of species on the basis of animal hair, dorsal guard hairs are generally used. De Marinis and Asprea (2006) noted that hairs from other body regions show similar characteristics to dorsal hair but are often less distinctive thus making identification more problematic. Hairs exhibit different morphological characteristics according to the animal species, and they are generally composed of the root, shaft, and tip. Furthermore, hair tissue consists of three layers from outside to inside: (1) the cuticle; (2) cortex; and (3) medulla (Oli, 1993). The size and shape of

\footnotetext{
Corresponding author: ahmetarpacik@ktu.edu.tr 0030-9923/2021/0006-2247 \$ 9.00/0

Copyright 2021 Zoological Society of Pakistan
}

medullary cells, cortex thickness and shape, and size and sequence of cells in the hair cuticle display individualized structures (Firat et al., 1998). The cortex consists of longitudinal and shrunken cells, which appear under a light microscope as a homogenous mass without any details. This layer provides limited information for differentiating different species (Teerink, 1991). The medulla is composed of shriveled dead cells, but unlike the cortex, these cells are clearly visible (Hausman, 1920; Teerink, 1991). The outermost layer, which is the cuticle, is composed of many overlapping transparent keratin scales (Teerink, 1991). The form of this layer and its structural characteristics and measurements are also used for species definition. Morphological and morphometric characteristics of hair, such as hair length and width, medullary scale and cuticle patterns, medullary index (MI), hair root, and other variables based on microscopy often help identify the origin of the hair and characterize the species, and it provides the opportunity to compare the hair structures of different species (Sato et al., 2006, 2010; Sahajpal et al., 2008; Yates et al., 2010; Tridico et al., 2014; Tremori et al., 2018). In defining the hair characteristics of the species, which belong to the same family, especially in the same genus, the morphological definition of only the medulla and cuticle characteristics is sometimes insufficient. In this case, performing morphometric measurements on the 
characteristics of medulla and cuticle would yield more accurate results.

Although several authors have contributed to this area of research (Moore et al., 1974; Koppiker and Sabnis, 1976; Debrot et al., 1982; Keller, 1984; Teerink, 1991; Wallis, 1993; Venkatraman et al., 1994; Chakraborty and De, 2001; Tóth, 2002; Debelica and Thies, 2009; Sar1 and Arpacik, 2018), knowledge of tricho-taxonomic studies of the family Canidae is still insufficient. Many of these studies include definitions of the morphological structures of only the medulla and cuticle. Detailed morphometric measurements have not been performed on these structures.

Turkey is home to three species of Canidae family (i) red fox ( $V$. vulpes); (ii) golden jackal (C. aureus); and (iii) gray wolf (C. lupus). Among these species, hunting of $C$. lupus has been prohibited by the Ministry of Agriculture and Forestry (MAF, 2019). Other species are available for hunting within the scope of hunting tourism (MAF, 2019). Despite the fact that these species prefer different habitats and foods, they usually share the same land in our country (Turan, 1984). Especially, large hunting mammals, game birds, and endangered wild animals are quite frequently hunted by these species (Turan, 1984). Furthermore, these species, especially $V$. vulpes, are sometimes subject to the illegal fur trade (IHA, 2018).

The purpose of this study was to use light microscopy on hair samples obtained from canid species with the aim of identifying their characteristics and differentiating between them. In order for the hair identification to conclude with more accurate results, morphometric measurements were performed on the structural characteristics of the hair and comparisons were made among the species. Hair study has been used in wildlife studies for species distribution, population density, dietary habits of the species, and illegal fur trading.

\section{MATERIALS AND METHODS}

\section{Samples collection}

In this study, hair samples obtained from $V$. vulpes, $C$. aureus, and $C$. lupus, which are the three common species in Turkey, were used (3 individual per species). Samples, which belonged to the male members of the canid species used in the study, were obtained from the Wildlife Museum located in the Wildlife Ecology and Management Department of Karadeniz Technical University. These samples were obtained from the members that were brought to the museum from the Eastern Black Sea Region of Turkey during autumn months. The hair samples were collected from the dorsolateral body of each specimen (Wallis, 1993). Dorsal guard hairs were collected from interscapular, lumbar and croup regions (IN, L, and
C, respectively) were collected from adult animals (Senthilkumar et al., 2018). From the IN, L, and C regions of the dorsal guard areas of each canid species, 30 hair samples were taken ( 1 individual per species). Therefore, a total of 270 hair samples were obtained from three canid species.

\section{Preparation of hair samples}

Each hair sample was cleaned with distilled water 2-3 times to remove dust and debris and then put in ether/alcohol (50:50) for 2 to $3 \mathrm{~min}$ to remove any fatty materials and then blot-dried (Kshirsagar et al., 2009). Each dried hair strand was treated with $70 \%$ hydrogen peroxide and $30 \%$ ammonia for about 1 to $2 \mathrm{~h}$ to bleach the hair, which helped form the line of differentiation between the cortex and medulla lucid, at which point the hair becomes transparent (De Marinis and Agnelli, 1993; Kshirsagar et al., 2009). The samples were placed in water to be thoroughly washed and then a series of samples were placed on the gelatin-treated solution while some were placed in liquid paraffin (Teerink, 1991). A morphological analysis was performed under the light microscope (Olympus bX41) with the 10X zoom for the hair root structure and $40 \mathrm{X}$ zoom for the medulla and the cuticle structures.

\section{Microscopic examination}

The mounted slides containing the hair were examined for morphological characteristics and micrometry (Kshirsagar et al., 2009). Microscopic characteristics of hair medulla and cuticula, such as composition, structure, pattern, margin form, and scale position, pattern, margin, and margin distance of hair were studied with help of the digital camera fitted on top of an optical light microscope (Kamalakannan, 2017). In this study, the hair classification system that was proposed by De Marinis and Asprea (2006) and Teerink (1991) was used. This classification was based on medulla margins, cortex width, and cellular structure, composition, and pattern (Teerink, 1991).

\section{Hair measurement}

The medullary, cuticle, cortex, and hair root structures from a total of 270 hair samples, which were obtained from the three different parts of the dorsal guard area of the $V$. vulpes, $C$. aureus, and $C$. lupus, were examined under the light microscope using both the $10 \mathrm{X}$ and $40 \mathrm{X}$ zoom; images were scaled and saved in JPEG format. A total of 270 hair samples, which were saved in JPEG format, were transferred to the Digimizer image analysis software (www.digimizer.com), and measurements were obtained from each photo. The diameter of the medulla and maximum diameters of the shaft and hair root values were 
measured in $\mathrm{m} \mu$ on each hair sample, and the resulting measurements were transferred to the Excel database (version 2013). In the present study, the maximum lengths of hair samples were measured with the help of a ruler and were recorded. In the present study, MI values were also calculated. MI is a ratio obtained by dividing the width of the medulla by the diameter of the hair at the point of the greatest shaft width (Carrlee and Horelick, 2011).

\section{Statistical analyses}

Data and measurements from all specimens were recorded and analyzed with the SPSS software (version 23). Due to the frequent occurrence of normal homogeneous distribution of samples, it was decided to use SPSS parametrical, dependent statistics. Data were statistically analyzed using SPSS with one-way analysis of variance (ANOVA). The differences among the means were determined using Duncan's and post-hoc tests. Statements of statistical significance were based on $p<0.05$.

\section{RESULTS}

The images belonging to the medulla, cuticle, and hair roots of the canid species under the light microscope are given in Figure 1 along with their corresponding hair structures. While the medullary structures of $C$. aureus and $C$. lupus had a vacuolated structure, a multiseriate structure was observed in the $V$. vulpes. Particularly, the medullary structures of the middle parts of certain hairs obtained from $C$. aureus were observed to be amorphous. Therefore, when analyzing the medullary structure of the hair belonging to the $C$. aureus, the hair had to be examined from the root to the tip under the light microscope instead of examining a certain part. Medullary compositions of the
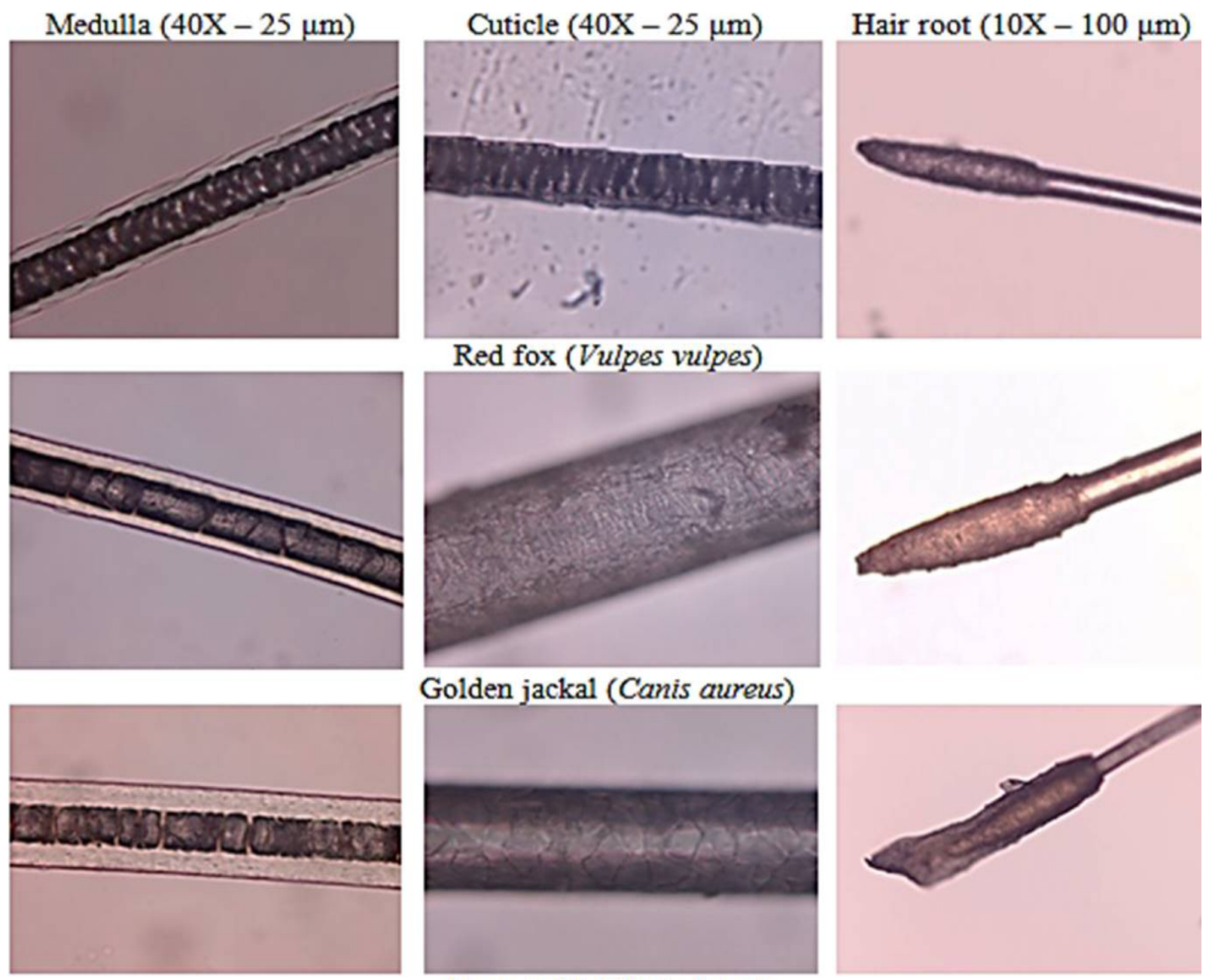

Gray wolf (Canis lupus)

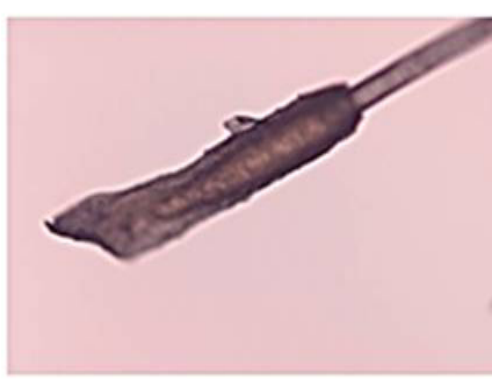

Fig. 1. Medullary, cuticle and hair root features of Canid species. 
canid species displayed an irregular unicellular structure. This structure was observed very prominently in $V$. vulpes and $C$. lupus. The medullary patterns of the canid species have a continuous structure. However, fragmented structures could sometimes be observed in the root and tip parts of the hair. The medullary sides of the species were observed to have irregular structures in general. The position of the cuticle scales was observed as transversal in position and showed a smooth scale margin. In general, the cuticle structure scale pattern the species was observed to be an irregular wave form. However, in some hair samples belonging to $C$. lupus, this structure was observed to be in an irregular mosaic form. Moreover, the scale pattern structure of $V$. vulpes was observed to be in regular form in some hair samples. The cortex widths of the both $C$. lupus and $C$. aureus were medium. $V$. vulpes had a narrower cortex width than the other two species. It was observed that the hair root shapes of the canid species were conical. The hair follicles of $C$. lupus were observed to be in the catagen stage with round root ends and attached follicular tissues. In $V$. vulpes and $C$. aureus, the hair samples were observed to have telogen structures with bulbous root tips without follicular tissue (Fig. 1).

Tables I and II show comparison of hair characteristics among the species and morphometric measurements of these characteristics from the three different parts of the dorsal guard areas.

Table I.- Intra-species analysis of variance (one way ANOVA) of mid shaft portion for dorsal guard hair features in canid species.

\begin{tabular}{llcc}
\hline Hair features & Species & Mean \pm SEM $(\mathbf{n}=\mathbf{9 0})$ & Min-Max \\
\hline Hair length & V. vulpes & $6.02 \pm 0.07^{\mathrm{a}}$ & $3.90-7.90$ \\
& C. aureus & $6.65 \pm 0.12^{\mathrm{b}}$ & $3.50-9.50$ \\
& C. lupus & $5.56 \pm 0.11^{\mathrm{c}}$ & $3.70-7.90$ \\
Medulla & V. vulpes & $33.16 \pm 1.04^{\mathrm{a}}$ & $12.51-55.80$ \\
diameter & C. aureus & $78.32 \pm 2.14^{\mathrm{b}}$ & $35.85-123.29$ \\
& C. lupus & $32.59 \pm 0.99^{\mathrm{a}}$ & $15.25-58.22$ \\
Hair diameter & V. vulpes & $47.01 \pm 1.34^{\mathrm{a}}$ & $21.37-73.60$ \\
& C. aureus & $107.63 \pm 2.58^{\mathrm{b}}$ & $55.08-157.58$ \\
& C. lupus & $77.17 \pm 1.45^{\mathrm{c}}$ & $38.41-110.22$ \\
Medullary & V. vulpes & $0.70 \pm 0.005^{\mathrm{a}}$ & $0.52-0.81$ \\
index & C. aureus & $0.72 \pm 0.005^{\mathrm{b}}$ & $0.58-0.82$ \\
& C. lupus & $0.42 \pm 0.006^{\mathrm{c}}$ & $0.23-0.56$ \\
Hair root & V. vulpes & $62.23 \pm 1.06^{\mathrm{a}}$ & $40.64-89.86$ \\
diameter & C. aureus & $102.30 \pm 1.75^{\mathrm{b}}$ & $61.20-145.19$ \\
& C. lupus & $136.27 \pm 2.98^{\mathrm{c}}$ & $69.93-206.72$ \\
\hline
\end{tabular}

$\mathrm{a}, \mathrm{b}, \mathrm{c}$, means for groups in homogeneous subsets are displayed (Subset for alpha $=0.05)$. The differences among means were determined using the Duncan test from Post-Hoc Test. Statements of statistical significance were based on $p<0.05$.
Looking at the average hair lengths of the canid species, it was observed that the longest hair mean value (mean \pm standard error $[\mathrm{SE}])$ was in C. aureus $(6.66 \pm 1.22$ $\mathrm{cm})$ followed by $V$. vulpes $(6.02 \pm 0.75 \mathrm{~cm})$ and finally $C$. lupus $(5.56 \pm 5.57 \mathrm{~cm})$. When the three different parts of the dorsal guard area were compared, the mean value for the longest hair was obtained in $V$. vulpes with $\mathrm{IN}=6.36 \pm$ $0.75 \mathrm{~cm}>\mathrm{L}=5.91 \pm 0.78 \mathrm{~cm}>\mathrm{C}=5.78 \pm 0.61 \mathrm{~cm}$ in the INpart followed by $C$. aureus with $\mathrm{L}=7.24 \pm 0.61 \mathrm{~cm}>$ $\mathrm{IN}=6.37 \pm 1.78 \mathrm{~cm}>\mathrm{C}=6.36 \pm 0.74 \mathrm{~cm}$ in the lumbar part and finally, by $C$. lupus with $\mathrm{L}=6.21 \pm 0.65 \mathrm{~cm}>\mathrm{C}=$ $5.62 \pm 0.48 \mathrm{~cm}>\mathrm{IN}=4.87 \pm 1.31 \mathrm{~cm}$ in the L part. While the shortest hairs in $V$. vulpes and $C$. aureus were identified in the $\mathrm{C}$ area, $C$. lupus had the shortest hair in the IN. As a result of the one-way ANOVA, significant differences were observed among the hair lengths of the species $(p<$ 0.05 ). Duncan's test for homogeneity of variance (oneway ANOVA) in the data for hair length values between different species showed significant homogeneity $(p<$ $0.05)$. Duncan's test also showed significant differences ( $p$ $<0.05$ ) in hair length values of the canid species.

The average medullary diameter were $78.32 \pm 20.96$, $33.16 \pm 10.18$, and $32.59 \pm 9.70 \mu \mathrm{m}$ in $C$. aureus, $V$. vulpes, and $C$. lupus, respectively. The widest medullary diameters were found in $V$. vulpes $(\mathrm{C}=40.06 \pm 8.81 \mu \mathrm{m}>\mathrm{IN}=29.78$ $\pm 9.34 \mu \mathrm{m}>\mathrm{L}=29.66 \pm 8.89 \mu \mathrm{m})$ in the $\mathrm{C}$ part followed by $C$. aureus $(\mathrm{L}=93.16 \pm 15.80 \mu \mathrm{m}>\mathrm{IN}=77.37 \pm 18.30$ $\mu \mathrm{m}>\mathrm{C}=64.44 \pm 18.27 \mu \mathrm{m})$ in $\mathrm{L}$ and in C. lupus $(\mathrm{L}=$ $36.71 \pm 9.69 \mu \mathrm{m}>\mathrm{IN}=31.97 \pm 9.96 \mu \mathrm{m}>\mathrm{C}=29.11 \pm 8.04$ $\mu \mathrm{m})$ in the L part. According to the results of the one-way ANOVA, significant differences were determined among the medullary diameter values $(p<0.05)$. According to Duncan's test of variance analysis, no significant difference was observed between the medullary diameters of $C$. lupus and V. Vulpes; however, the medullary diameter of $C$. aureus displayed significant differences when compared to these other two species $(p<0.05)$ as shown in Tables I and II. This study has shown that medullary diameter values by themselves cannot be used to differentiate among the canid species. Particularly, in determining the species of the species that belong to the same family with similar medullary structures, the MI should be taken into consideration.

Average hair diameter values were observed to be $107.63 \pm 25.34,77.17 \pm 14.24$, and $47.00 \pm 13.18 \mu \mathrm{m}$ in $C$. aureus, C. lupus, and $V$. vulpes. When the parts were analyzed, the average widest hair diameters were found in $\mathrm{C}$ in $V$. vulpes $(\mathrm{C}=55.17 \pm 12.14 \mu \mathrm{m}>\mathrm{IN}=43.49 \pm 11.81$ $\mu \mathrm{m}>\mathrm{L}=42.37 \pm 11.90 \mu \mathrm{m})$ followed by $C$. aureus in $\mathrm{L}(\mathrm{L}$ $=123.91 \pm 20.07 \mu \mathrm{m}>\mathrm{I}=108.79 \pm 20.48 \mu \mathrm{m}>\mathrm{C}=90.18$ $\pm 23.57 \mu \mathrm{m})$ and $C$. lupus in $\mathrm{L}(\mathrm{L}=81.16 \pm 13.65 \mu \mathrm{m}>\mathrm{C}$ $=76.23 \pm 11.98 \mu \mathrm{m}>\mathrm{I}=74.14 \pm 16.28 \mu \mathrm{m})$. The one-way 
ANOVA concluded that there were significant differences among the hair diameter values of the species $(p<0.05)$.

Table II.- Intra-species analysis of variance (one way ANOVA) of mid shaft portion of dorsal guard hair from interscapular (IN), lumbar (L) and croup (C) regions in canid species.

\begin{tabular}{|c|c|c|c|c|}
\hline $\begin{array}{l}\text { Hair } \\
\text { features }\end{array}$ & Species & Region & $\begin{array}{c}\text { Mean } \pm \text { SEM } \\
(\mathbf{n}=\mathbf{3 0})\end{array}$ & Min-Max \\
\hline Hair & V. vulpes & IN & $6.36 \pm 0.13^{\mathrm{a}}$ & $5.00-7.90$ \\
\hline \multirow[t]{8}{*}{ length } & & $\mathrm{L}$ & $5.91 \pm 0.14^{b}$ & $3.90-7.50$ \\
\hline & & $\mathrm{C}$ & $5.78 \pm 0.11^{\mathrm{b}}$ & $4.50-6.80$ \\
\hline & C. aureus & IN & $6.37 \pm 0.31^{\mathrm{a}}$ & $3.50-9.50$ \\
\hline & & $\mathrm{L}$ & $7.24 \pm 0.11^{\mathrm{b}}$ & $6.10-8.20$ \\
\hline & & $\mathrm{C}$ & $6.36 \pm 0.13^{\mathrm{a}}$ & $5.00-8.20$ \\
\hline & C. lupus & IN & $4.86 \pm 0.23^{\mathrm{a}}$ & $3.70-7.90$ \\
\hline & & $\mathrm{L}$ & $6.21 \pm 0.11^{\mathrm{b}}$ & $5.00-7.50$ \\
\hline & & $\mathrm{C}$ & $5.61 \pm 0.08$ & $5.00-6.70$ \\
\hline Medulla & V. vulpes & IN & $29.78 \pm 1.65^{\mathrm{a}}$ & $12.51-50.05$ \\
\hline \multirow[t]{7}{*}{ diameter } & & $\mathrm{L}$ & $29.65 \pm 1.57^{\mathrm{a}}$ & $13.47-55.80$ \\
\hline & C. aureus & IN & $77.37 \pm 3.23^{\mathrm{a}}$ & $35.85-104.65$ \\
\hline & & $\mathrm{L}$ & $93.16 \pm 2.79^{b}$ & $52.37-123.29$ \\
\hline & & $\mathrm{C}$ & $64.43 \pm 3.23^{\mathrm{c}}$ & $37.19-109.04$ \\
\hline & C. lupus & $\mathrm{IN}$ & $31.97 \pm 1.76^{\mathrm{a}}$ & $15.25-57.24$ \\
\hline & & $\mathrm{L}$ & $36.71 \pm 1.71^{\mathrm{b}}$ & $22.62-58.22$ \\
\hline & & $\mathrm{C}$ & $29.10 \pm 1.42^{\mathrm{a}}$ & $18.66-56.91$ \\
\hline Hair & V. vulpes & IN & $43.49 \pm 2.09^{\mathrm{a}}$ & $24.25-73.60$ \\
\hline \multirow[t]{8}{*}{ diameter } & & $\mathrm{L}$ & $42.37 \pm 2.10$ & $21.37-70.27$ \\
\hline & & $\mathrm{C}$ & $55.17 \pm 2.14^{\mathrm{b}}$ & $26.38-70.89$ \\
\hline & C. aureus & IN & $108.79 \pm 3.62^{\mathrm{a}}$ & $60.92-139.50$ \\
\hline & & $\mathrm{L}$ & $123.91 \pm 3.54^{b}$ & $70.44-157.58$ \\
\hline & & $\mathrm{C}$ & $90.18 \pm 4.17^{\mathrm{c}}$ & $55.08-148.75$ \\
\hline & C. lupus & IN & $74.13 \pm 2.88^{\mathrm{a}}$ & $38.41-110.22$ \\
\hline & & $\mathrm{L}$ & $81.15 \pm 2.41^{\mathrm{a}}$ & $53.80-109.40$ \\
\hline & & $\mathrm{C}$ & $76.23 \pm 2.12^{\mathrm{a}}$ & $53.99-108.97$ \\
\hline Medullary & V. vulpes & IN & $0.68 \pm 0.01^{\mathrm{a}}$ & $0.52-0.81$ \\
\hline \multirow[t]{8}{*}{ index } & & $\mathrm{L}$ & $0.69 \pm 0.008^{\mathrm{a}}$ & $0.59-0.79$ \\
\hline & & $\mathrm{C}$ & $0.72 \pm 0.008^{b}$ & $0.63-0.81$ \\
\hline & C. aureus & $\mathrm{IN}$ & $0.70 \pm 0.01^{\mathrm{a}}$ & $0.58-0.79$ \\
\hline & & $\mathrm{L}$ & $0.75 \pm 0.008^{\mathrm{b}}$ & $0.61-0.82$ \\
\hline & & $\mathrm{C}$ & $0.71 \pm 0.007^{\mathrm{a}}$ & $0.64-0.80$ \\
\hline & C. lupus & IN & $0.43 \pm 0.01^{\mathrm{a}}$ & $0.23-0.54$ \\
\hline & & $\mathrm{L}$ & $0.44 \pm 0.01^{\mathrm{a}}$ & $0.34-0.56$ \\
\hline & & $\mathrm{C}$ & $0.37 \pm 0.008^{b}$ & $0.29-0.52$ \\
\hline Hair root & $V$. vulpes & IN & $62.58 \pm 1.59^{\mathrm{a}, \mathrm{b}}$ & $49.04-89.86$ \\
\hline \multirow[t]{8}{*}{ diameter } & & $\mathrm{L}$ & $57.85 \pm 1.55^{\mathrm{a}}$ & $43.74-78.12$ \\
\hline & & $\mathrm{C}$ & $66.27 \pm 2.05^{\mathrm{b}}$ & $40.64-85.43$ \\
\hline & C. aureus & $\mathrm{IN}$ & $107.50 \pm 2.68^{\mathrm{a}}$ & $76.54-134.72$ \\
\hline & & $\mathrm{L}$ & $107.13 \pm 2.76^{\mathrm{a}}$ & $74.03-145.19$ \\
\hline & & $\mathrm{C}$ & $92.26 \pm 2.94^{\mathrm{b}}$ & $61.20-136.57$ \\
\hline & C. lupus & IN & $134.19 \pm 4.68^{\mathrm{a}}$ & $75.61-193.02$ \\
\hline & & $\mathrm{L}$ & $157.21 \pm 4.75^{b}$ & $117.21-206.72$ \\
\hline & & $\mathrm{C}$ & $117.38 \pm 3.40^{\mathrm{c}}$ & $69.93-152.48$ \\
\hline
\end{tabular}

For statistical details, see Table I.
Duncan's test for homogeneity of variance (one-way ANOVA) in the data for hair diameter values among different species showed significant homogeneity of variance $(p<0.05)$. Duncan's test also showed significant differences among hair diameter values of canid species $(p$ $<0.05)$ as shown in Tables I and II.

Average MI values were identified to be $0.72 \pm 0.52$, $0.70 \pm 0.56$, and $0.42 \pm 0.64 \mu \mathrm{m}$ in C. aureus, V. Vulpes, and C. lupus, respectively. When the parts were analyzed, the average widest $\mathrm{MI}$ values were found in $\mathrm{C}$ in $V$. vulpes $(\mathrm{C}$ $=0.73 \pm 0.04 \mu \mathrm{m}>\mathrm{L}=0.70 \pm 0.05 \mu \mathrm{m}>\mathrm{IN}=0.68 \pm 0.07$ $\mu \mathrm{m})$ followed by $C$. aureus in $\mathrm{L}(\mathrm{L}=0.75 \pm 0.04 \mu \mathrm{m}>\mathrm{C}=$ $0.71 \pm 0.04 \mu \mathrm{m}>\mathrm{IN}=0.70 \pm 0.06 \mu \mathrm{m})$ and C.lupus in $\mathrm{L}(\mathrm{L}$ $=0.45 \pm 0.06 \mu \mathrm{m}>\mathrm{IN}=0.43 \pm 0.07 \mu \mathrm{m}>\mathrm{C}=0.38 \pm 0.05 \mu \mathrm{m})$. The one-way ANOVA concluded that there were significant differences between the MI values of the species $(p<$ 0.05 ). Duncan's test for homogeneity of variance (oneway ANOVA) in the data for MI values among different species showed significant homogeneity of variances $(p<$ $0.05)$. Duncan's test also showed significant differences in MI values of canid species $(p<0.05)$ as shown in Tables I and II. The morphological structures of the medulla and cuticles of $C$. lupus and $C$. aureus were very similar to each other. In this study, it was observed that the MI values could be successfully used for differentiating members of the canid species.

Diameter measurements of the widest parts of the hair roots of the canid species concluded that the average root diameter values were $136.27 \pm 29.25,102.30 \pm 17.19$, and $62.23 \pm 10.37 \mu \mathrm{m}$ in C. lupus, C. aureus, and $V$. vulpes, respectively. When the parts were analyzed, the average widest hair root diameter value was found in the $\mathrm{C}$ part in $V$ vulpes $(\mathrm{C}=66.27 \pm 11.60 \mu \mathrm{m}>\mathrm{IN}=62.58 \pm 9.0 \mu \mathrm{m}>$ $\mathrm{L}=57.85 \pm 8.78 \mu \mathrm{m})$ followed by the $C$. aureus in the IN area $(\mathrm{IN}=107.51 \pm 15.16 \mu \mathrm{m}>\mathrm{L}=107.13 \pm 15.60 \mu \mathrm{m}>$ $\mathrm{C}=92.26 \pm 16.64 \mu \mathrm{m})$ and $C$. lupus in the $\mathrm{L}$ area $(\mathrm{L}=$ $157.22 \pm 26.90 \mu \mathrm{m}>\mathrm{IN}=134.19 \pm 26.48 \mu \mathrm{m}>\mathrm{C}=117.39 \pm$ $19.26 \mu \mathrm{m})$. The one-way ANOVA indicated that there were significant differences among the hair root diameter values of the species $(p<0.05)$. Duncan's test for homogeneity of variance (one-way ANOVA) applied to the data for hair root diameter values among different species showed significant homogeneity of variance $(p<0.05)$. Duncan's test also showed significant differences in hair root values of canid species $(p<0.05)$.

\section{DISCUSSION}

Identification of the medulla and cuticle structures of the dorsal guard hairs of wild animals is one of the cheapest and easiest methods for species determination. Previous studies addressing the medulla and cuticle features of 
canid species presented similar results as the present study (Moore et al., 1974; Koppiker and Sabnis, 1976; Teerink, 1991; Wallis, 1993; Keller, 1984; Chakraborty and De, 2001; Tóth, 2002; Debelica and Thies, 2009; Sar1 and Arpacik, 2018). The medullary structure of $V$. vulpes was shown to be vacuolated by many authors (Teerink, 1991; Chakraborty and De, 2001; Debelica and Thies, 2009). However, it was shown to have amultiseriate structure (Tóth, 2002; Sarı and Arpacık, 2018). In study by Koppiker and Sabnis (1976) concerning C. aureus, it was explained that the medullary pattern of the hair had a fragmented structure. In the present study, it was observed that medullary patterns of the middle parts of the hair structures in canid species were generally continuous; however, fragmented structures were observed in the areas close to the hair root and the tip (Koppiker and Sabnis, 1976). Debelica and Thies (2009) defined the scale pattern of $C$. lupus as a regular wave. In the present study, this structure was identified as an irregular wave as a general trend. However, in some of the examined hair, this structure was identified as an irregular mosaic form as demonstrated by Keller (1984). Keller (1984) determined that the scale pattern in the $C$. aureus was an irregular mosaic; however, in the present study, this structure was not observed in $C$. aureus.

Hair length and diameter and medullary diameter and MI of the hair vary not only in the overall group of canid species but also within same species. Furthermore, the medullary and cuticle structures of hair may be different in the root, shaft, and tips of the hair in addition to the hair from the different parts of the body. The studies on hair structure measurements of the canid species are quite limited. In studies on the hair lengths, medullary index, and the hair diameters in the dorsal guard of the $V$. vulpes, Teerink (1991) found the maximum length as $6 \mathrm{~cm}$ and hair diameter between 90 and $120 \mu \mathrm{m}$, while Firat et al. (1998) calculated the average hair diameter as $57.75 \mu \mathrm{m}$, and Chakraborty and De (2001) found an average hair length of $5.2 \mathrm{~cm}$, average hair diameter of $42.7 \mu \mathrm{m}$, and average MI of 0.72 . Tóth (2002) concluded that the average hair length was $4.54 \mathrm{~cm}$, average hair diameter was $106.5 \mu \mathrm{m}$, and the average MI was 0.74. Debelica and Thies (2009) identified the average hair diameter as $<82 \mu \mathrm{m}$. In the present study, in contrast to other studies, it was determined that the average hair length in the dorsal guard of the $V$. vulpes was $6.02 \mathrm{~cm}$, which is longer than mentioned in the literature. In the present study, the average diameter of the hair in the middle area was identified as $47 \mu \mathrm{m}$, which was similar to the results obtained by Chakraborty and De (2001). In the present study, determined the average medulla index was determined as 0.70 , which was close to the results obtained by Chakraborty and De (2001) and Tóth (2002).
In the studies on the C. aureus, in terms of hair lengths, MIs, and hair diameters in the middle parts in their dorsal guard areas, Venkatramanet et al. (1994) measured the average hair diameter as $63.8 \mu \mathrm{m}$. Chakraborty and De (2001) determined the average hair length as $5.2 \mathrm{~cm}$, hair diameter as $76.5 \mu \mathrm{m}$, and average MI as 0.67 . In the present study, the identified diameter value was higher than the value measured by Venkatramanet et al. (1994) and Chakraborty and De (2001) with respect to the average hair diameters $(107.63 \mu \mathrm{m})$. Average hair length and MI values, which were higher than the values obtained by Chakraborty and De (2001) for average hair length and average medulla index values $(6.66 \mathrm{~cm}$ and 0.72$)$, were measured.

In the studies on the C. lupus, in terms of the lengths, MI, and hair diameters in the middle parts in their dorsal guard areas, Firat et al. (1998) found the average hair diameter was $55.25 \mu \mathrm{m}$. Chakraborty and De (2001) determined the average hair length as $10.7 \mathrm{~cm}$, average hair diameter as $116 \mu \mathrm{m}$, and average medulla index as 0.55. Debelica and Thies (2009) measured the average hair diameter as $133 \mu \mathrm{m}$. In the present study, unlike the other studies, the average hair length was determined as 5.57 $\mathrm{cm}$, diameter of the hair in the middle part as $77.17 \mu \mathrm{m}$, and the average medullary index as 0.42 .

With respect to the identification of the hair in canid species, the diameter of the hair root can also be used. These values also vary according to the species. As a result of the measurements made on the diameters of the widest parts of the hair roots in canid species, the average root hair diameter values were $136.27,102.30$, and $62.23 \mu \mathrm{m}$ in $C$. lupus, C. aureus, and in $V$. vulpes, respectively. When the hair roots of these three species were examined, they were found to have a conical structure.

Morphological analysis of the medulla and cuticle structures by themselves may not provide accurate results in the diagnosis of hair structures of $C$. aureus and $C$. lupus among the canid species. Medullary and cuticle structures of these two species have quite similar characteristics. However, morphometric measurements performed on these structures would give more accurate results for species identification. The statistical analysis concluded that there were significant differences between hair lengths, medullary diameters, hair diameters, MIs, and hair roots of C. aureus and C. lupus.

Differences were observed between the findings in the present study and findings from the previous studies on morphological structures and measurements of hair structures in canid species. These differences may have occurred due to the factors related to the environment, geography, temperature, age, gender, and subspecies. Obtaining hair samples from different parts of the body, 
examining different parts of the hair, and the number of samples are among the factors that may create differences in the results. With respect to the diagnosis of these species and while taking the literature studies as a reference, it seems that selecting those studies that were conducted in regions close to the study area would conclude with more accurate results.

\section{CONCLUSIONS}

This study concluded that the medulla and cuticle structures of $C$. aureus and C. lupus were morphologically similar to each other; however, $V$. vulpes differed from these two species presenting a multiseriate characteristic with respect to its medullary structure, in particular. Especially, in order to obtain more accurate results in the diagnosis of the hair structures of $C$. aureus and $C$. lupus, measurements, and statistical analyses should be performed on the hair characteristics. Measurements of the hair structures of canid species provide important information for the diagnosis of the species with respect to statistical analyses. Therefore, it was concluded that by combining all microscopic characteristics, it would be possible to characterize the hair of canid species at the species level. It was concluded that this study on canid species can be used effectively in forensic, taxonomic, paleontological, archaeological, anthropological, wildlife, and ecological studies.

\section{ACKNOWLEDGEMENT}

Author is thankful to İbrahim Kiraz for his laboratory supports for the study.

\section{Statement of conflict of interest}

The authors have declared no conflict of interests.

\section{REFERENCES}

Carrlee, E. and Horelick, L., 2011. The Alaska Fur ID Project: A virtual resource for material identification. Am. Inst. Conserv. Hist. Artist. Works, 11: 149-171.

Chakraborty, R. and De, J.K., 2001. Identification of dorsal guard hairs of five Indian species of the family Canidae (Carnivora: Mammalia). Mammalia, 65: 483-494. https://doi.org/10.1515/ mamm.2001.65.4.483

Chang, B.S., Hong, W.S., Lee, E., Yeo, S.M., Bang, I.S., Chung, Y.H., Lim, D.S., Mun, G.H., Kim, J., Park, S.O. and Shin, D.H., 2005. Ultramicroscopic observations on morphological changes in hair during 25 years of weathering. Foren. Sci. Int., 151: 193-200. https://doi.org/10.1016/j. forsciint.2004.12.037

De Marinis, A.M. and Agnelli, P., 1993. Guide to the microscope analysis of Italian mammals hairs: Insectivora, Rodentia and Lagomorpha. Italian J. Zool., 60: 225-232. https://doi. org/10.1080/11250009309355815

DeMarinis,A.M. andAsprea,A., 2006. Hairidentification key of wild and domestic ungulates from southern Europe. Wildl. Biol., 12: 305-321. https://doi. org/10.2981/0909-6396(2006)12[305:HIKOWA]2 .0. $\mathrm{CO} ; 2$

Debelica, A. and Thies, M.L., 2009. Atlas and key to the hair of terrestrial Texas mammals (No. 55). Museum of Texas Tech University. https://doi. org/10.5962/bhl.title.142652

Debrot, S., Fivaz, G., Mermod, C. and Weber, J.M., 1982. Atlas des poils de mammifèresd'Europe. Institut de Zoologie, Université de Neuchâtel.

Firat, U.B., Armutak, A., Bozkurt, H.H., Çörekçi, İ., Aktaş, A. and Dağlioğlu, S., 1998. Comparative morphological examination on the hair structure of certain domestic and wild animals that live in Turkey. Istanbul Üniv. Vet. Fakül. Derg., 24: 275292.

Hardy, M.H., 1992. The secret life of the hair follicle. Trends Genet., 8: 55-61. https://doi. org/10.1016/0168-9525(92)90350-D

Hausman, L.A., 1920. Structural characteristics of the hair of mammals. Am. Natural., 54: 496-523. https://doi.org/10.1086/279782

Kamalakannan, M., Manna, C.K. and De, J.K., 2017. Identification of dorsal guard hair of tibetan antelope Pantholops hodgsonii (Abel, 1826) (Bovidae: Artıdactyla: Mammalıa). Int. J. Sci. environ. Technol., 6: 1426-1429.

Keller, A., 1984. Etude de la structure fine des jarresdorsaux de quelques Canidé ssauvageset domestiques du genre canis (Mammalia: Canidae). Rev. Sui. Zool., 91: 973-992. https://doi. org/10.5962/bhl.part.81593

Koppikar, B.R. and Sabnis, J.H., 1976. Identification of hairs of some Indian mammals. J. Bombay nat. Hist. Soc., 73: 5-20.

Kshirsagar, S.V., Singh, B. and Fulari, S.P., 2009. Comparative study of human and animal hair in relation with diameter and medullary index. Indian J. Foren. Med. Pathol., 23: 105-8.

Lyne, A.G. and Short, B.F., 1965. Biology of the skin and hair growth. Proceedings of a symposium held at Canberra, Australia, August 1964, Amsterdam. 
Elsevier

IHA, 2018. Sacks of fox fur were seized in Haydarpaşa Port. https://www.iha.com.tr/haber-haydarpasaro-ro-limaninda-cuvallar-dolusu-tilki-kurku-elegecirildi-723477/

MAF, 2019. Central hunting commission decision (2019-2020). Ministry of Agriculture and Forestry.

Meyer, W., Schnapper, A. and Hulmann, G., 2002. The hair cuticle of mammals and its relationship to functions of the hair coat. J. Zool., 256: 489-494. https://doi.org/10.1017/S0952836902000535

Moore, T.D., Spence, L.E. and Dugnolle, C.E., 1974. Identification of the dorsal guard hairs of some mammals of Wyoming. Wyoming Game and Fish Department.

Oli, M.K., 1993. A key for the identification of the hair of mammals of a snow leopard (Panthera uncia) habitat in Nepal. J. Zool., 231: 71-93. https://doi. org/10.1111/j.1469-7998.1993.tb05354.x

Sari, A. and Arpacık, A., 2018. Morphological hair identification key of common mammals in Turkey. Appl. Ecol. environ. Res., 16: 4593-4603. https:// doi.org/10.15666/aeer/1604_45934603

Sato, H., Matsuda, H., Kubota, S. and Kawano, K., 2006. Statistical comparison of dog and cat guard hairs using numerical morphology. Foren. Sci. Int., 158: 94-103. https://doi.org/10.1016/j. forsciint.2005.04.041

Sato, I., Nakaki, S., Murata, K., Takeshita, H. and Mukai, T., 2010. Forensic hair analysis to identify animal species on a case of pet animal abuse. Int. J. Legal Med., 124: 249-256. https://doi.org/10.1007/ s00414-009-0383-2

Senthilkumar, S., Gnanadevi, R., Kannan, T.A., Arunaman, C.S. and Ramesh, G., 2018. Microanatomical observations of hair in domestic animals: A comparative study. J. Ent. Zool. Stud., 6: $1925-1929$.
Teerink, B.J., 1991. Hairs of West-European mammals. Cambridge University Press.

Tóth, A.M., 2002. Identification of Hungarian Mustelidae and other small carnivores using guard hair analysis. Acta Zool. Acad. Sci. Hungar., 48: 237-250.

Tremori, T.M., Garcia, F.M., Flórez, L.M., Gonçalves, B.P., Ferraz de Camargo, B.W.D., Gwinnett, C., Roberto-Teixeria, C. and Sousa-Rocha, N., 2018. Hair analysis of mammals of Brazilian wildlife for forensic purposes. Open J. Anim. Sci., 8: 335-345. https://doi.org/10.4236/ojas.2018.83025

Tridicio, S.R., Houck, M.M., Kirkbride, K.P., Smith, M.E. and Yates, B.C., 2014. Morphological identification of animal hairs: Myths and misconceptions, possibilities and pitfalls. Foren. Sci. Int., 238: 101-107. https://doi.org/10.1016/j. forsciint.2014.02.023

Turan, N., 1984. Game and wild animals in TurkeyMammalian. OGM. I. Bask1, I. Cilt, Ongun Kardeşler Matbaacılık Sanayii, Ankara, pp. 178.

Sahajpal, V., Goyal, S.P., Jayapal, R., Yoganand, K. and Thakar, M.K., 2008. Hair characteristics of four Indian bear species. Sci. Justice, 48: 8-15. https:// doi.org/10.1016/j.scijus.2007.05.001

Venkataraman, K., De, J.K. and Tandon, S.K., 1994. Ultrastructure studies of hairs of seventeen species of carnivore mammals using scanning electron micrographs. Rec. zool. Surv. India, 94: 145-149.

Wallis, R.L., 1993. A key for the identification of guard hairs of some Ontario mammals. Canadian J. Zool., 71: 587-591. https://doi.org/10.1139/z93-080

Yates, B.C., Espinoza, E.O. and Baker, B.W., 2010. Forensic species identification of elephant (Elephantidae) and giraffe (Giraffidae) tail hair using light microscopy. Foren. Sci. med. Pathol., 6: 165-171. https://doi.org/10.1007/s12024-0109169-6 